\title{
Development of business processes in the innovatively active organizations
}

\author{
Salima Makhosheva ${ }^{1, *}$ and Elena Vasilyeva ${ }^{2}$ \\ ${ }^{1}$ Institute of Informatics and Problems of Regional Management, Branch of Federal Scientific Center, \\ Kabardino-Balkarian Scientific Center, RAS, 37a I. Armand Str., Nalchik, Russia, 360004 \\ ${ }^{2}$ Moscow State University of Civil Engineering, 26 Yaroslavskoye sh., Moscow, Russian Federation, \\ 129337
}

\begin{abstract}
The research objective is to formulate some suggestions for the improvement of business processes modeling in the innovative activity of the organizations for the increase in its efficiency. Having studied the existing approaches to the business processes management, theoretical works and practical experience, the authors conclude, that the standard models, developed for traditional business processes of the organizations, are insufficiently effective for the innovatively active organizations. The main objectives of modeling of business processes of innovatively active enterprise were formulated, possible tools are studied. According results of the research, some samples of business modules and subprocesses, adapted for the innovatively active organizations, are developed. The results, received by authors, can be useful for the increase in efficiency of the existing business models, as well as for the information support during the innovative projects creation and implementation. The innovatively active organizations can use the authors' proposals to support the managerial decisions in the conditions of the need for reengineering of the operating business processes, as well as during new products launch to the market. Bodies of state regulation can use the obtained results during the formation of the innovative development strategy.
\end{abstract}

\section{Introduction}

Modern Russia has to overcome the lag from some foreign countries during the transition to the innovation economy. Nowadays the issues of the innovative development are subjects to close attention, both at the level of state regulation, and at the level of the separate enterprises.

Nevertheless, the Russian economy is characterized by the use of outdated schemes of development of the management systems, based generally on the linearly-and-functional approach. This circumstance (along with others, such as insufficiency of investment resources, imperfection of technique of efficiency evaluation of innovations, etc.) acts as the restriction for the development of the innovatively active organizations. Unlike the "turnkey" foreign technologies, the development of domestic producers of innovations are

\footnotetext{
*Corresponding author: elena.chibisova_metr@mail.ru
} 
quite rare, and modeling of the innovation business processes (both managing and operating ones) acts as a strength of the organization management system, allowing to operate the efficiency of the innovation activity in the conditions of risk and uncertainty.

The authors studied the numerous works concerning the research subject. The theoretical bases of the innovation projects management and their efficiency are analyzed and reflected in the works by such domestic and foreign scientists as Brigham Yu., Erkhardt M., Birman G., Schmidt S., Unsociable persons A. N., Asaul M.A., Kolesnikov A.M., Rodionov D.G., Kudryavtseva T.Yu., Dzhamay E.V., Bessarabov A.M., Gracheva M.V., etc. Works by M. Hummer and J. Ciampi, B. Andersen, P. Allen, A. Byyorn, J. Vutten, T. Davenport, V. Dyoming, F. Kotler, H. Kumamoto, E. Larson, H.V. Nimvegen, D. Palistrant, M. Robson, M. Roter, G. Simon, S. Sato, F. Uallakh, A. Harrison, J. Harrington, E. Henley A.-W. Scheer, J. Short, E. Esseling, etc. [Ошибка! Источник ссылки не найден., Ошибка! Источник ссылки не найден., Ошибка! Источник ссылки не найден., Ошибка! Источник ссылки не найден., 1] are devoted to the research of business processes. V.M. Dzhukh, D.A. Kornilov, Yu.N. Smirnov, Yu.F. Telnov, Yu.N. Fomina, O.S. Cheremnykh, S.V. Cheremnykh, E.V. Chernetsova, E.I. Yablochnikov, etc. [6] consider the process-and-task methodology of re-engineering and business process modeling of the organization. Considering the specifics of business processes in the sphere of innovations, the process approach in the relation to the innovative activity which makes the subject of works by such foreign scientists as T. Amy, R. André, J. Valor, B. Goden, M. Goldsmith, H. Devenport, V. Deming, K. Dzhayn, P. Druker, M. Leybold, S. Narvekar, P. Nelson, S. Mayne, V. Millar, M. Porter, I. Rogers, R. Rotvel, I. Sommervil, F. Hesselbeyn, I. Shot, J. Schumpeter, etc. [7, 8, 9, 10, 11] is of special interest.

Nowadays the issues of modeling of traditional business processes of the organization are considered sufficiently. At the same time these issues are worked out for the innovation activity, and especially its types to a lesser extent. The existence of separate types of the innovations, connected with technologies, marketing and the organizations assumes the importance of the identification of the specifics of business processes in these spheres. This matter is reflected in the scientific literature not fully. Besides, the available fundamental and applied models of innovations do not always consider the specifics of the Russian reality.

That causes the relevance of subject of this research and does its results useful for the organizations of various industries during the innovation projects implementation.

\section{Materials and Methods}

The research was carried out with the use of complex of scientific methods, regularities, economic-and-mathematical analysis, modeling, static and comparative analysis.

The authors also relied on the provisions of the innovation theory, theory of management of the organization, the theory of modeling of the innovative development, the theory of process management as well as on the related concept of business processes and reengineering. Modern techniques of forecasting of the economic events and processes, relevant models of state regulation of the economy also play important role. The crossdisciplinary approach, which the authors stand by, and which was described in the previous works by one of the authors $[12,13,14]$ considers the key problems, the organizations and the innovation managers face in any economic system.

Working on the research, the authors analyzed:

- standard legal documents;

- analytical reports;

- statistical data of Federal State Statistics Service of the Russian Federation; 
- analytical materials of National information center on science and innovations; Vnesheconombank Innovation Fund; Fund of Development of the Center of Development and Commercialization of New Technologies, Non-profit organization (Skolkovo Fund); Fund of assistance to innovations, Fund of perspective research.

The authors used IDEF family modeling languages for the creation of samples of business process models of innovation active enterprises. Microsoft Visio program has been used for the graphical representation of models.

\section{Results}

Business process modeling is the reflection of subjective vision of the real-life processes in the organization by the means of graphic, tabular and text methods of representation. Business process modeling considers not only how the organization functions in general, how it is connected with the external organizations, clients and producers, but also how the each employee's work is established. Modeling is one of the methods of the improvement of the organization activity as well as of the improvement of the quality and efficiency of its functioning.

The main sphere of the use of business models is the business process reengineering. Besides, the creation of models "as is" and "as will be" and also the evolution from the first model in the second one is supposed. Thus, "any innovation enterprise is a complex system; its activity includes the realization of dozens of thousands of mutually influencing business challenges" [15].

The main purpose of business process modeling is the increase in the efficiency of the innovation activity of the organization. For this purpose, the results of the process and its value, minimization of cost and the period of realization attract particular interest during the analysis. On the basis of the studied sources [16, 17, 18, 19, 20, 21, 22] we can point out the main objectives of business process modeling of innovatively active enterprise:

1. Process description. By the means of modeling it is possible to trace process from the beginning to the end. Modeling allows to take a detached view of processes and to reveal the ways to improve the technology of making managerial decisions, which will increase the process efficiency.

2. Process regulation. Business process modeling creates some instructions and algorithms of the process accomplishment, i.e. as the process can be implemented. If to observe these instructions, then it is possible to achieve desirable results and performance of process.

3. Establishment of communications between the processes. Business process modeling demonstrates communications between business processes and the rules, which they have to carry out.

4. Ensuring understanding of the firm structure and dynamics of the processes, happening in it.

5. Ensuring understanding of the current problems of the organization and the opportunities of their solving.

6. Ensuring understanding that customers, consumers and developers understand the purposes and tasks of the organization equally.

7. Creation of the base for forming of requirements to the software automating business processes of the organization.

Analyzing scientific works by domestic and foreign researchers [Ошибка! Источник ссылки не найден., Ошибка! Источник ссылки не найден., Ошибка! Источник ссылки не найден., Ошибка! Источник ссылки не найден., 18, 23, 24, Ошибка! Источник ссылки не найден.], the existing approaches to the business process management, we make the following conclusions. 
1. Many existing business process models, are limited in the sense that they consider only one process separately and allow to improve this process, but do not consider the impact of changes on other processes. Such a situation when the improvements in the modelled process can have harmful business impact in general, is possible. To be absolutely sure that business process modeling brings benefits, the whole business has to be simulated and estimated. Thus the complete model of the whole business has to be the final purpose of modeling.

2. The majority of traditional business process models are linear and static by the nature, each new stage is not initiated before the previous stage is finished. The main disadvantage of the majority of the traditional consecutive approaches to the process of modeling is that they try to provide dynamic process with the two-dimensional freeze frame depicting. The disadvantage of the use of static models is that they do not facilitate the result of the changed process which has to be simulated.

Various information technologies and tools are used for business process modeling in modern conditions. It simplifies the management process, updates and reduces the analysis time. Such modeling tools of business processes in the innovation sphere include the IDEF languages, representing the series of the modeling languages which were originally developed for the use in the field of software development [26, 27]. IDEF0 and IDEF3 are most suitable for business process modeling. These tools were developed for business analytics, underwent a long and careful debugging and grinding. It is much simpler to create model without mistakes with their help, than without application of this standard.

When using IDEF0 language, work is constructed on the function design (i.e. activities, similar to that which is used in flowcharts and the diagrams EPC). IDEF3 is focused on the temporary aspect of business processes and also describes two different types of modeling languages: for the description of streams of processes and for the description of transitions of conditions of object.

According to aforesaid we offer samples of models of the business modules and subprocesses, adapted for innovatively active organizations (Fig. 2, 3).

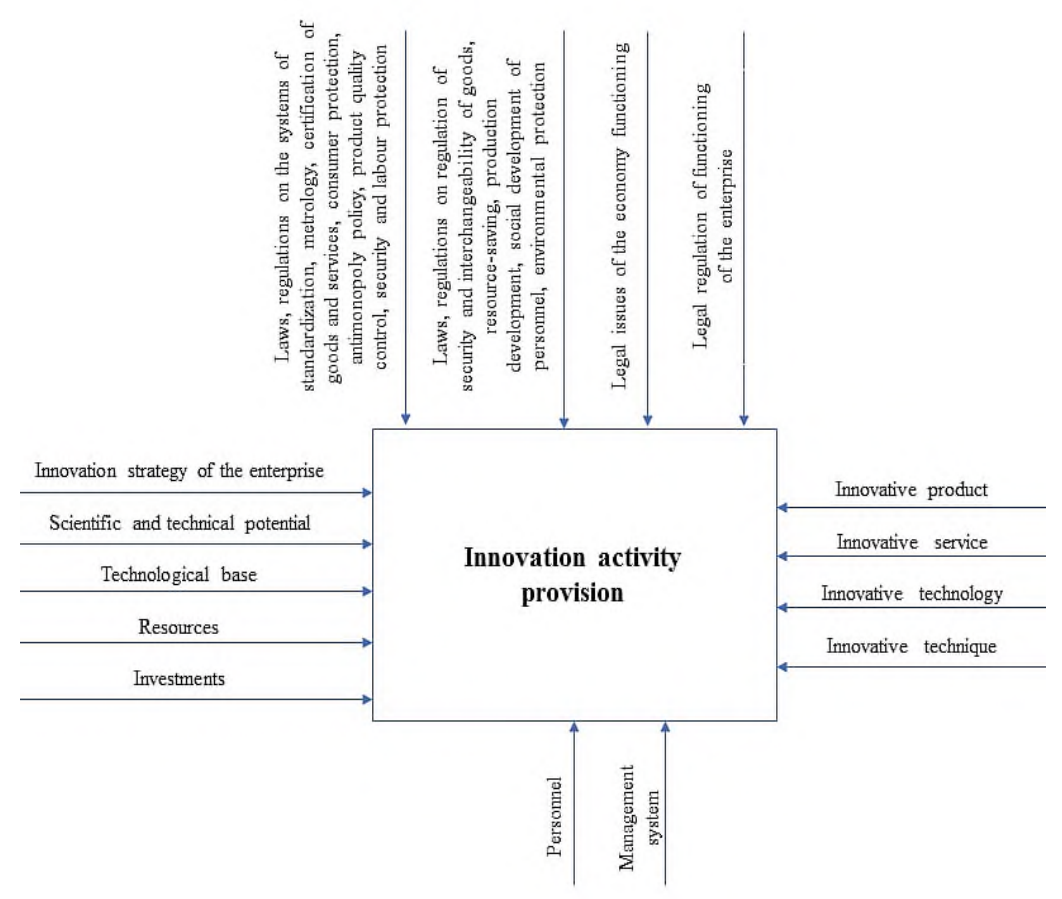


Fig. 1. IDEF0 model of the Innovation Activity Provision business module in the innovation organizations.

The IDEF0 models constructed by different analysts for the simplest situations will be almost identical.

IDEF0 model does not describe the sequence of actions. The relations between various functions indicate their dependences; that can mean the causal relation, but it is optional. The lack of the temporary sequence in IDEF0 language allows users to model the content of business, without forcing them to explain how business is performed.

On the other hand, the lack of the sequence in the diagram is one of disadvantages of IDEF0 which IDEF3 overcomes.

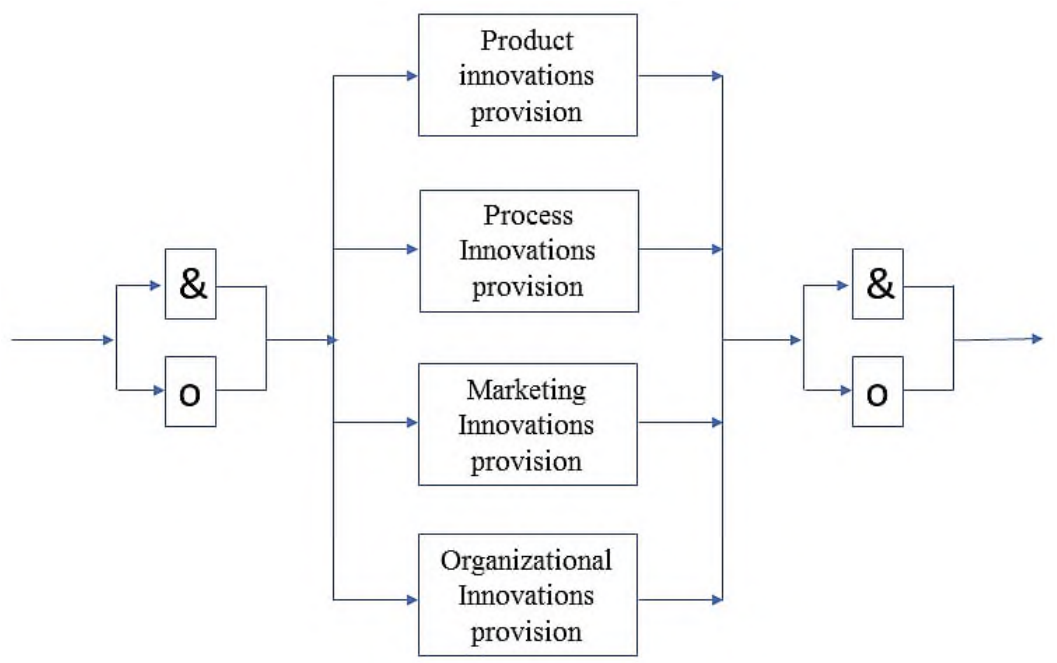

Fig. 2. IDEF3 model of the Innovation Activity Provision business module in the innovation organizations.

Explanations of the symbols:

- $\quad \&$ - synchronous "and"

- O - synchronous "or"

- $\quad$ fan-in junction $+\boldsymbol{\&}-$ All the previous processes are completed simultaneously

- $\quad$ fan-in junction $+\mathbf{O}$ - One or several previous processes are completed simultaneously

- $\quad$ fan-out junction $+\boldsymbol{\&}$ - All the previous subsequent start simultaneously

- $\quad$ fan-out junction $+\mathbf{O}$ - One or several previous subsequent start simultaneously

\section{Discussion}

The emphasis on functional decomposition is also considered to be a disadvantage of the IDEF modeling languages [15]. Big models can cover numerous diagram and that complicates the overview of the general process. Though at the highest level of decomposition a "root" diagram exists, the functions on this diagram do not reveal the decomposition depth. For this reason, the IDEF models often are followed by the "tree of models" diagram, which describes the relations between various IDEF diagram (Fig. 3). 


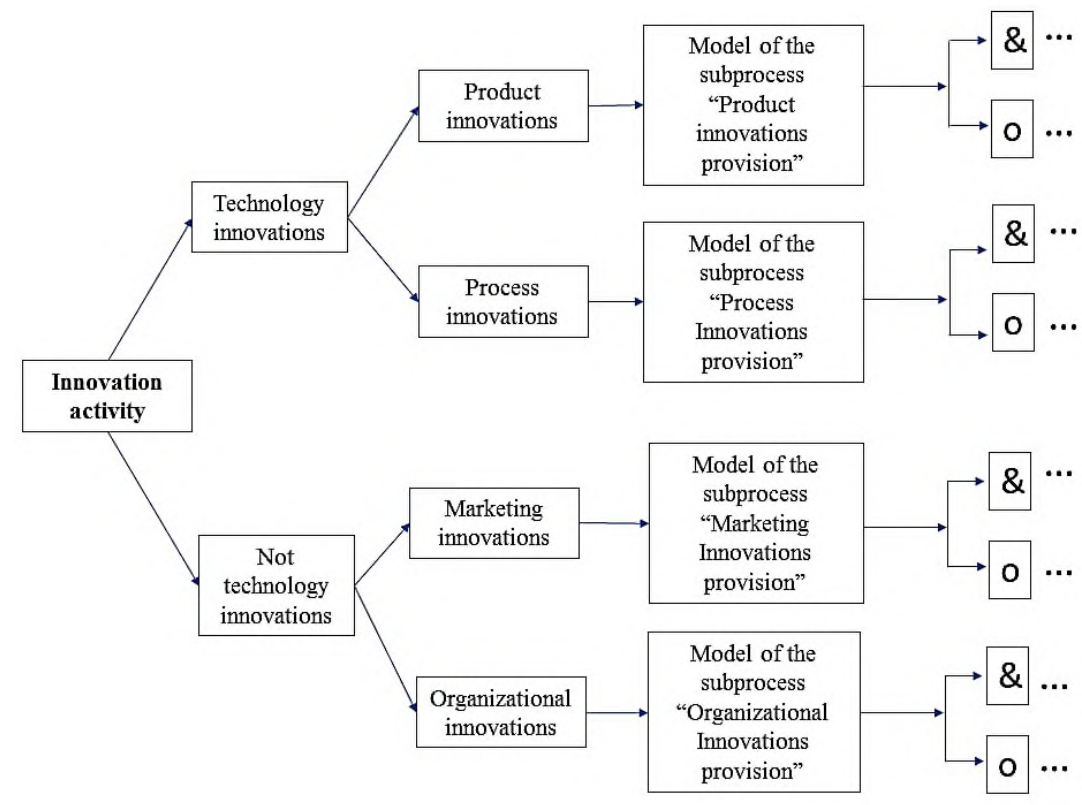

Fig. 3. The simplified image of "tree of models" (it is created by the authorb according to classification of innovations).

Other modeling languages (BPMN, etc.) [12] have significant amount of concepts and terms, high level of occurrence (e.i. demand more time for studying them, in comparison with IDEF0 and IDEF3). Besides, they can lead to the creation of very big diagrams, which are difficult for their practical use by analysts of the organizations, managers and tops.

Some experts $[27,28,30,31,32]$ suggest to carry out the transformation of IDEF models to UML diagrams for the automated synthesis of business process models. The corresponding software (converter) is already created [33,34,35]. The authors consider them to be not obligatory, but useful for the solution of economic and technical-andtechnological tasks, such as:

- automated construction with the minimum labour costs of business processes simulation models;

- wide use of simulation modeling during the engineering and business process reengineering in economics and technology, promoting the improvement of labour productivity.

\section{Conclusions}

Business process modeling helps managers and heads of the organizations to maintain the coordination between processes, at the same time keeping the orientation to general strategies of the organization and guaranteeing, that the operational tasks and actions which are carried out by the team members actually help the organization to realize the strategy. Innovations begin with the changing business models.

According to the aforesaid features, the specifics of the innovation activity make an essential mark on the necessary maintenance of the business process models, which are different from the models, created for traditional activities. The standard models, which are already developed for traditional business processes of the organization, are not applicable for the innovatively active organizations. 
Nowadays the IDEF languages are the most real tools for the practical application for business process modeling at the innovation enterprise.

The recommendations of authors include the following:

a) to consider specifics of the innovation activity during modeling,

b) to consider processes in complex, but not in separation from each other to, estimate how each of them influences business in general,

c) to develop not static model, but the model considering the possibility of changes;

d) not to be limited purely functional decomposition, to create a tree of models if necessary.

Considering the results of the conducted research and the formulated recommendations, the authors have offered the conceptual model allowing to satisfy the need for necessary changes of business processes for the innovation activity, to reveal bottlenecks of the innovation process, to choose management tools, information support and assessment in work of the innovation-active organization correctly.

\section{Acknowledgements}

The reported study was funded by RFBR, project number 20-010-00766.

\section{References}

1. M. Robson, F. Ullakh, Practice guidance on business process reengineering (Audit, UNITY, Moscow, 1997)

2. J. Henley, H. Kumamoto, Reliability of technical systems and risk assessment (Mechanical engineering, Moscow, 1984)

3. A. Harrison, Busines Process: Their Nature And Properties, Examining Business Process Re-Engineering (Cranfield University, School of Management, London, 1995)

4. J. Harrington, K.S. Esseling, H.V. Nimvegen, Business process optimization. Documenting, analysis, management, optimization (ALPHABET B-micro, St. Petersburg, 2002)

5. H. Davenport, Process innovation: reengineering work through information technology (Harvard Business School Press, Boston, Mass, 1993)

6. N.A. Dimitriadi, V.M. Dzhukha, I.V. Mishurova, O.B. Chernenko, European Proceedings of Social and Behavioural Sciences, 68-76 (2020)

7. T. Ami, R. Sommer, International Journal of Services and Standards 2(3), 249-261 (2007)

8. R. Andreu, J. Ricart, J. Valor, Knowledge and Process Management 4(2), 114-25 (1997)

9. E. Rogers, Diffusion of Innovations (Macmillan Publishing Co., Inc., 1983)

10. R. Rothwell, International Marketing Review 11(1), 7-31 (1994)

11. A.-W. Scheer, ARIS -Business Process Modeling (Springer, Berlin, 2000)

12. E.Yu. Vasilieva, Fundamental and applied research in the field of management, economics and trade, 27-31 https://www.elibrary.ru/download/elibrary_39566634_30019509.pdf

13. E.Yu. Vasilieva, Russian economic online journal 3 (2019) www.erej.ru/Articles/2019/Vasilieva.pdf

14. E. Vasilyeva, Y. Krupnov, E3S Web of Conferences 164, 10037 (2020) 
15. I.I. Ishmuradova, Worldscience: problems and innovations 2, 53-55 (2017)

16. V. Eliferov, V.V. Repin, Process approach to management. Business process modeling (Standards and quality, Moscow, 2004)

17. S.I. Kremleva, Quality management methods 5, 68 (2004)

18. V.N. Babich, A.G. Kremelv, Innovation business process model (UNITY, Moscow, 2016)

19. B.N. Gerasimov, Management and business administration 4, 17-26 (2017)

20. I.G. Yershov, O.V. Mikhailov, Basic research 6-2, 381-385 (2016)

21. M.A. Rastov, Business and entrepreneurship Journal 1-31(42-3), 397-400 (2014)

22. E.O. Naumenko, On the management models the innovation process of at the enterprise in modern conditions, http://ej.kubagro.ru/2006/04/03

23. O. Noran, Proc. $6^{\text {th }}$ International Conference on Enterprise Information Systems (ICEIS 2004) 3, 674-682 (2004)

24. W.M.P. Van der Aalst, A.H.M. Hofstede, B. Kiepuszewski, A.P. Barros, 7th International Conference on Cooperative Information Systems (CoopIS 2000) 1901, $18-29$ (2000)

25. E. Anoshkina, E. Markovskaya, A. Mottaeva, As. Mottaeva, E3S Web of Conferences 210, 13022 (2020) https://doi.org/10.1051/e3sconf/202021013022

26. A.V. Merzlyak, Creative economy 9(11), 1351-1370 doi:10.18334/ce.9.11.2168

27. E.A. Babkin, Knyazkin Accusative, M.S. Shitkova, Business information scientist 2(16), 31-42 (2011)

28. Cheol-Han Kim, R.H. Weston, A. Hodgson, Kyung-Huy Lee, Computers in Industry 50(1), 35-56 (2003)

29. A. Mottaeva, J. Stepanova, N. Meshkova, G. Semenova, European Journal of Sustainable Development 10(1), 705-723 (2021) Doi: 10.14207/ejsd.2021.v10n1p705

30. G.N. Hubayev, S.N. Shirobokova, European journal of economics and management sciences 4 (2016) https://cyberleninka.ru/article/n/preobrazovanie-idef3-modeley-vuml-diagrammy-dlya-avtomatizirovannogo-sinteza-imitatsionnyh-modeley

31. G.N. Hubayev, O.V. Homeland, S.N. Shirobokova, Modern high technologies. Regional supplement 2(46) (2016) https://cyberleninka.ru/article/n/avtomatizirovannyy-sintez-imitatsionnyh-modeleyuniversalnyy-instrumentariy-dlya-ekspress-otsenki-i-optimizatsii-zatrat-resursov-v

32. S.N. Shirobokova, S.M. Scherbakov, State Technical University of Saratov Bulletin 1 (2008) https://cyberleninka.ru/article/n/kontseptsiya-i-metodika-avtomatizirovannogoformirovaniya-imitatsionnyh-modeley-delovyh-protsessov

33. G.N. Hubayev, S.N. Shirobokova, Yu.V. Tkachenko, E.V. Titarenko, Patent. Automated converter of IDEFO models in language workflow charts UML «ToADConverter» («ToADConverter») CeBIT 2015, Catalog of the Russian companies development. Ministry of Education and Science of the Russian Federation (Hanover, 2015)

34. E. Ganebnykh, O. Lezhnina, J. Zhukova, V. Kashintseva, E3S Web of Conferences 210, 10008 (2020) https://doi.org/10.1051/e3sconf/202021010008

35. O.N. Soboleva, T.A. Burtseva, E.A. Barmina, E.V. Ganebnykh, P.V. Tokareva, Contribution to Economics, 565-574 (2017) DOI: 10.1007/978-3-319-60696-5_71 